\title{
Radiological findings as predictors of mortality in Quebec asbestos workers
}

\author{
F D K LIDDELL AND J C MCDONALD
}

From the TUC Centenary Institute of Occupational Health, London School of Hygiene and Tropical Medicine, London, UK

ABSTRACT Two cohorts of chrysotile miners and millers in Quebec were selected to study the extent to which chest radiographs taken while still employed predict mortality. The paper presents mainly findings in much the larger cohort, which consisted of 4559 men (two-thirds past workers) whose latest radiograph had been assessed by one of six experienced readers into what became the UICC/Cincinnati (U/C) classification; by the end of 1975 there had been 1543 deaths in this cohort. The findings were generally confirmed in the other cohort, comprising 988 current male workers, who had been examined in 1967-8 by questionnaires on respiratory symptoms and smoking and by lung function tests, and for whom all six readers had assessed their 1966 radiographs into the $\mathrm{U} / \mathrm{C}$ classification; 130 men had died by the end of 1975 .

Men with any radiographic abnormality, heavy dust exposure, or a history of cigarette smoking had relative risks (RRs) of total mortality greater than unity. Death from pneumoconiosis was associated with small parenchymal opacities, usually irregular, of profusion $1 / 1$ or more, and with heavy dust exposure but not with smoking. Most who died from lung cancer had smoked cigarettes, or had been heavily exposed to dust, or both. Small parenchymal opacities were present in most but not all the excess deaths due to lung cancer. Deaths from other malignant diseases showed no consistent dust or $x$-ray patterns. RRs of deaths from most other causes were raised for certain radiographic features. Failures in forecasting mortality were primarily due to deaths in which asbestos-related disease was not the primary cause but may have been a contributing factor.

The main findings validated the U/C classification convincingly, particularly as the films had been taken as routine and were of modest quality. Despite objective rules for the reading and the fact that all six readers were contributing to the development of the classification, there was inevitably some observer variation. The importance of radiographic technique and the need for careful control of the reading is evident.

Our results provide support for the use of the chest radiograph for surveillance of asbestos workers, and for environmental monitoring. Its protective value for individual workers, however, is limited to the extent that radiological progression continues after withdrawal from exposure, and by the carcinogenic risk associated with dust already retained.

In 1966 a team at McGill University started a major investigation of the health of Quebec chrysotile miners and millers. The fundamental inquiry was into the mortality of a birth-cohort of over 11000

Requests for reprints either to Professor Liddell, Department
of Epidemiology and Health, McGill University, 3775 Uni-
versity Street, Montreal, Quebec, Canada H3A 2B4, or to
Professor McDonald, TUC Centenary Institute of Occupa-
tional Health, London School of Hygiene and Tropical
Medicine, Keppel Street, London WC1E 7HT.

Received 3 July 1979

Accepted 10 December 1979 workers.1-5 Two other important components were: (a) cross-sectional studies in 1967-8 of 1015 current male employees, relating respiratory symptoms, lung function measurements, and radiological changes to accumulated dust exposure, age, and smoking habits, with some examination of the interrelation of the pulmonary and radiological signs; and $(b)$ an extended "cross-sectional" investigation of radiographic changes in 11207 men.

The findings from the cohort mortality study have been remarkably consistent ${ }^{4}$ in follow-up to four points in time $(1966,1969,1973$, and 1975). To the 
end of 1975, the cohort suffered 4463 male deaths; the overall excess mortality from 1926, the first year Quebec data were available, to 1975 was $2 \%$ at Asbestos and $10 \%$ at Thetford Mines, much the dustier of the two chrysotile producing regions in Quebec. Among men employed at least 20 years there were clear excesses in those exposed to the heavier dust concentrations. The dose-response was effectively linear for lung cancer and for pneumoconiosis. Deaths from lung cancer occurred in non-smokers, and their exposure-response line was steeper than for smokers. There were ten male deaths (and one of a woman) from mesothelioma, all pleural. If the only subjects studied had been the 1904 men with at least 20 years' employment in the lower dust concentrations (averaging 6.6 million particles per cubic foot or about 20 fibres $/ \mathrm{ml}$ ) excess mortality would not have been considered statistically significant, except for pneumoconiosis.

In 1967-8 an age-stratified random sample of 1015 current male employees was subjected to a standard questionnaire on smoking and respiratory symptoms, and to lung function tests. Dust exposure accumulated until November 1966 was calculated for each man by the methods of Gibbs and Lachance. ${ }^{6}$ The prevalence of persistent cough and phlegm (bronchitis) was related to age and smoking habits and, perhaps, in non-smokers and light smokers, also to dust exposure; breathlessness on exercise was related to age and dust exposure (table 1(a)) but not to smoking. ${ }^{7}$ In the same sample Becklake et $a l^{9}$ found that inspiratory capacity, forced vital capacity, and forced expiratory volume were associated with dust exposure (table 1(b)). In effectively the same sample a posteroanterior chest radiograph taken in 1966, or occasionally slightly earlier, had been assessed in 1967 by six experienced readers into the fore-runner (details available on request) of the UICC/Cincinnati classification, ${ }^{10}$ and the relations between radiological changes and pulmonary function were examined. ${ }^{11}$ Even in workers whose radiographs showed no evidence of parenchymal disease, vital capacity and forced vital capacity may have been slightly reduced; in the presence of slight parenchymal changes vital capacity and forced vital capacity were impaired a little further, and vital capacity and exercise-minute ventilation were more generally related to radiological abnormality. For any given grade of parenchymal change, function was a fraction more impaired when pleural thickening or calcification, or both, were also present. Rossiter et al $\mathbf{1 2}$ reported on radiographic changes in 11207 male production workers; among the 6127 aged 36 to 65 at last employment or in November 1966, the prevalence rose with increasing accumulated dust exposure (table 1(c)).

An important need remained: to relate mortality, the response of ultimate epidemiological importance, to earlier signs and symptoms. A limited study of mortality in relation to radiographic changes was reported by McDonald et al. ${ }^{2}$ Among those in the mortality cohort traced to the end of 1969 , chest radiographs were available for 5082 men, of whom 785 had died. At Thetford Mines, 97 deaths in those with parenchymal changes on radiograph (with or without pleural changes) were observed, compared with 64 expected on the basis of death rates in men without $x$-ray changes. In the excess 33 deaths 24 were attributed to respiratory causes. At Asbestos the difference between the mortality of those with and without $x$-ray changes was less.

We report a project, described in detail by Liddell, ${ }^{13}$ that exploited the material already collected from all these investigations. Its main objective was to answer the question: "To what extent can radiological changes in those who have been exposed to asbestos dust predict mortality?"

Table 1 Signs and symptoms in relation to exposure to asbestos dust

\begin{tabular}{|c|c|c|c|c|c|c|}
\hline & \multicolumn{6}{|c|}{ Accumulated dust exposure (mpcf:y) } \\
\hline & $<10$ & $\begin{array}{l}10 \\
<100\end{array}$ & $\begin{array}{l}100 \\
<200\end{array}$ & $\begin{array}{l}200 \\
<400\end{array}$ & $\begin{array}{l}400 \\
<800\end{array}$ & $\geqslant 800$ \\
\hline $\begin{array}{l}\text { (a) Breathlessness (\%) } \\
\text { (b) Inspiratory capacity (1) } \\
\text { (c) Radiographic changes (\%) }\end{array}$ & $\begin{array}{l}5 \cdot 0 \\
3 \cdot 12\end{array}$ & $\begin{array}{c}16 \cdot 4 \\
2 \cdot 79\end{array}$ & $\begin{array}{c}23 \cdot 8 \\
2 \cdot 83\end{array}$ & $\begin{array}{c}24 \cdot 4 \\
2.63\end{array}$ & $\begin{array}{c}28 \cdot 8 \\
2 \cdot 55\end{array}$ & $\begin{array}{c}38 \cdot 0 \\
2 \cdot 47\end{array}$ \\
\hline $\begin{array}{l}\text { Small opacities ( } 1 / 0 \text { or greater): irregular } \\
\text { Pleural thickening (grade } 1 \text { or greater) }\end{array}$ & $\begin{array}{l}3 \cdot 7 \\
2 \cdot 6\end{array}$ & $\begin{array}{l}3.5 \\
3.8\end{array}$ & $\begin{array}{l}6 \cdot 3 \\
5 \cdot 1\end{array}$ & $\begin{array}{l}7 \cdot 2 \\
4 \cdot 7\end{array}$ & $\begin{array}{l}9 \cdot 9 \\
6 \cdot 8\end{array}$ & $\begin{array}{r}13 \cdot 0 \\
8.6\end{array}$ \\
\hline
\end{tabular}

(a) Age-corrected prevalence, adjusted for smoking by equivalent average method of standardisation ${ }^{8}$ (McDonald et al ${ }^{7}$ table 4).

(b) Means, in non-smokers, corrected to standard age, height, and weight (Becklake et al table 3). These workers, considered this the best discrimination between dust-exposure groups. The standard deviation of IC, after correction, was 0.51 1 .

(c) Prevalence standardised for age and years of employment, and "averaged" over Asbestos and Thetford Mines (Rossiter et al ${ }^{12}$ tables 3, 4, and 5). 
Materials and methods

\section{DEFINITION OF COHORTS}

Two study cohorts were set up.

Cohort 1 was a subset of the mortality cohort of all 11379 subjects, born 1891-1920, who had worked for at least a month in the Quebec asbestos production industry. Only men qualified for the present subset, and they had to have had at least one chest radiograph taken while still employed in the industry. The last radiograph before leaving had been assessed in 1967 by one of six experienced readers (at the second stage of the study described by Rossiter et $a l^{12}$ into what became the UICC/ Cincinnati classification of radiographs, later accepted with minor changes as the ILO U/C (1971) international classification. ${ }^{14}$ Over 5000 men satisfied these criteria, but to preserve independence, those 603 who also qualified for cohort 2 (see below) were excluded; thus cohort 1 consisted of 4559 men. Tracing had been carried out to the end of 1975 , by which time 1543 men $(33.8 \%)$ were known to have died and $2957(64.9 \%)$ to have survived, with 59 $(1.3 \%)$ lost to view. The lower mortality and loss rates, compared with those reported by McDonald et $a l^{5}$ arose because all those in cohort 1 were $x$ rayed, and so had been working in or after 1936 at Asbestos, and in the late 1940s at Thetford Mines. They were thus considerably younger than the men in the main cohort.

Cohort 2 was selected from the 1015 men still employed in November 1966 who had been the subjects in the cross-sectional studies of respiratory symptoms and function and had had their 1966 routine chest radiograph assessed by all six readers. For one reason or another (probably most importantly that at least one reader had considered a film unreadable), a full set of six readings could not be assembled for $2.7 \%$, leaving 988 men in cohort 2 . The sampling had been heavily weighted towards older men, excluding altogether those less than 21 years old. About $85 \%$ of the men were interviewed and tested in the summer of 1967 , the remainder in the spring of 1968 . The age at time of test ranged from 22.1 years to 66.5 years. All 988 men were traced to the end of $1975 ; 858(86.8 \%)$ were still alive but $130(13.2 \%)$ had died.

An important difference in the criteria for selection of the two cohorts must be emphasised; death within a year of the latest radiograph would select a man into cohort 1 but (usually) out of cohort 2. Thus a man invited to attend for examination in 1967-8 who died before his appointment would be included instead in cohort 1 . This difference is not, of course, limited to the late 1960s; indeed of the 116 deaths in cohort 1 before 1951, half were due to accidents $(31.9 \%)$ or respiratory tuberculosis $(16.4 \%)$.

DATA AVAILABLE

For each man in cohort 1 we had available not only the full reading (by one of six readers) of his latest radiograph during employment but also: his date of birth; whether first employed at Asbestos or Thetford Mines (the two mining areas of Quebec); whether alive in 1976, or known to have died, in which case we also had year of death, and cause of death in the great majority $(99.2 \%)$, or lost to view before the end of 1975, with the date of loss; the date of his first employment in the Quebec asbestos industry; the length of his gross and net service in that industry (until November 1966); the dust exposure (measured in mpcf $\cdot y)^{6}$ accumulated during his gross service; and his smoking habit, obtained from questionnaires administered to almost all still living in the 1970s and to the relatives of the great majority of those who had died after 1950 (smoking habits were unknown for 244 men, or $5.4 \%$ of cohort 1,169 of these or $3.7 \%$ of the cohort having left work before 1951). Great effort had been exerted to ensure that the allocation of $x$-ray films to readers was at random, ${ }^{12}$ and there was strong evidence that this randomisation had been entirely successful (see below).

For each man in cohort 2 we had available not only the full reading by all six readers of his 1966 radiograph but also: his date of birth; whether first employed at Asbestos or Thetford Mines; whether alive in 1976, or dead, with year of death, and cause of death for all but two; the date of his first employment in the Quebec asbestos industry; the length of his gross and net service in that industry until November 1966; the dust exposure (mpcf-y) accumulated to November 1966; his smoking habit as elicited by interview in 1967 or 1968; the answers to a respiratory symptoms questionnaire at that time; certain lung function measurements then; and height and weight.

\section{ANALYTICAL METHODS}

For reasons discussed by Liddell et $a l^{3}$ the basic analyses were carried out using a priori reasoning, and the "man-years method" exactly as applied to the main mortality cohort. ${ }^{5}$ For cohort 1 , the "study interval" started at the end of recorded employment, on average about six months after radiography. The 116 deaths before 1951 were excluded from the present analyses. For cohort 2, the study interval started at the time of interview, on average about 15 months after radiography.

In cohort 1 the 1427 deaths observed 1951 to 1975

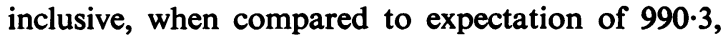


led to SMR (all causes) $=1 \cdot 44$, much higher than 1.09 in the full cohort. The explanation lies mainly in death at work or soon after retirement, which automatically selected into cohort 1 . Their average age at termination was 47 years (see also table 2), 10 years older than in the full cohort in which substantially fewer early deaths would thus have been expected. In cohort 1 over one-quarter of deaths occurred before the end of the year after that in which employment ceased, and their comparatively large number would allow the possibility of examining whether they could have been predicted from a radiograph taken only a fairly short time before death. Other differences, also tending to explain the enhanced SMR in cohort 1 , were that both net service and accumulated dust exposure were greater than in the complete cohort-that is, 18.2 years and 317 mpcf $\cdot y$ compared with $10 \cdot 5$ years and 202 mpcf $\cdot y$.

A major disadvantage of the man-years method is that, strictly, it requires the subdivision of the cohort into "subcohorts" according to the various factors of interest and that these subcohorts remain mutually exclusive. Even in cohort 1 the variables we wished to study were at least nine, and to maintain mutual exclusivity there would have had to be over 500 subcohorts; on average they would have consisted of only nine subjects of whom three would have died from any cause. Such an approach was not feasible, particularly as several variables had to be considered at several levels and others would subdivide the cohort quite unequally. In cohort 2 , with several more factors of interest and much smaller numbers, the difficulties were even greater. Therefore, separation into subcohorts was made, one factor at a time, in the clear understanding that the classifications were in no sense independent of each other.

The radiographic features examined were as listed in table 4. In addition each subject was classified as radiologically "normal" or "less-than-normal"; to be normal there had to be no record of change (profusion of small opacities $0 /-$ or $0 / 0$ for both rounded and irregular shapes; no large opacities; no record of pleural thickening, whether of the walls or affecting the costophrenic angles, the diaphragm or the cardiac border; no record of pleural calcification; and no "additional symbols"). In cohort 1 just two-thirds of the subjects were normal; in cohort 2 , where all six assessments had to be normal, less than one-third of the subjects were classed normal. For each radiographic feature, the complete cohorts were subdivided afresh, and the less-than-normal subjects may have appeared in several subcohorts defined by the presence of specific features. Two further analyses were carried out for both cohorts, again without regard for independence, as follows: (a) accumulated dust exposure (divided at $300 \mathrm{mpcf} \cdot \mathrm{y})$ and $(b)$ smoking habit (see tables 2 and 3 ).

There are various ways in which observed $(O)$ and expected (E) deaths may be compared, but despite its drawbacks, the simple ratio between them $(\mathrm{O} / \mathrm{E})$ still seems most appropriate. ${ }^{3}$ It can be seen to be an SMR, standardisation being not only by age but by era of death. It has further advantages over other ways of relating Os to Es in the ease with which it may be partitioned in analysis by $\chi^{2}$ (by the methods described in general by Armitage ${ }^{15}$ and, with particular reference to mortality studies, by Liddell et $a l^{3}$ ). For this paper, relative risk (RR) is defined as the ratio of SMRs. Differences between subcohorts were examined by a modification of the usual $\chi^{2}$ procedure: many values of this statistic were computed, and as they are not independent, no statement of "statistical significance" can be justified.

To study the "failures" of radiology to predict mortality where it should have done, we adopted the following approaches, arguing a posteriori. Firstly, we studied the $x$-ray readings of all cases of death due to pneumoconiosis and lung cancer, and, because of its special interest, mesothelioma, and examined the provenance of those with normal and less-than-normal films. Further, in cohort 1 we carried out two case-control studies, as follows. For each of the 31 deaths from pneumoconiosis and for each of the 118 from lung cancer, we selected a control born in the same year (or occasionally a year earlier) and known to have survived to a greater age than the case. Each control was selected from among men whose radiographs had been assessed by the reader who had also assessed the film of the case. Where there were several eligible controls, the choice was made by a process of strict randomisation.

Because cohort 1 was much the larger and suffered proportionately higher mortality, this paper is based mainly on findings from this cohort, but they were generally confirmed from cohort 2 , as will be indicated. The relative importance of respiratory symptoms, lung function measurements, and radiological signs, as assessed from cohort 2 after a longer period of follow-up has been completed, will be discussed elsewhere.

\section{Results}

A PRIORI REASONING

Tables 2 and 3 describe the men in the two cohorts according to their ages at the start of the study intervals. For cohort 1, this was the time of leaving employment in the Quebec asbestos mining industry 
(or at November 1966), and the radiograph had been taken, on average, about six months previously. For cohort 2, the study interval started at the time of test in 1967 or 1968 , while the radiograph would have been taken in 1966 or late 1965 . Table 2 shows the prevalence of the main radiographic features: the trends found in cohort 2 (table 3 ) were as similar as could be expected in the light of the different provenances of the cohorts. Although, in cohort 2, the older men were shorter than the younger, this did not account for the clear trend in forced vital capacity, while the older the men the higher the prevalence of breathlessness. Correlations between the various radiographic scores, environmental factors, and smoking were reasonably similar in the two cohorts; the highest were among the radiographic findings, and these were positively associated with exposure to dust. The coefficients of correlation of smoking habit with the other variables were all small (less than 0.05 in cohort 1 and than 0.09 in cohort 2).

The 4559 men in cohort 1 had been classified into six "sets" according to which reader had assessed their radiographs. These sets were compared for size, number lost to view, proportion who had died, distribution by cause of death, distribution by quinquennium of birth, average age at last job, average net service, and average accumulated dust exposure to test the "null" hypothesis; none of the test statistics came close to the conventional level of statistical significance. It would therefore seem that the randomisation had achieved its purpose in equalising the six sets of subjects, so that differences between them in terms of radiographic assessment or relations of such assessments to mortality or other factors were almost certainly due to differences between the readers. In fact the proportion of "less-than-normal" subjects, in the six sets, varied from $20.9 \%$ to $39.9 \%$. The gradient with age seen at

Table 2 Description of cohort 1 (4559 men)

\begin{tabular}{|c|c|c|c|c|c|}
\hline & \multicolumn{5}{|c|}{ Age at termination } \\
\hline & $<35$ & $35-44$ & $45-54$ & $55-64$ & $\geqslant 65$ \\
\hline $\begin{array}{l}\text { No of men } \\
\text { Percentage from Asbestos } \\
\text { Net service (yr) } \\
\text { Accumulated dust exposure (mpcf ·y) } \\
\text { Average dust "concentration" (mpcf) } \\
\text { Percentage smoking cigarettes } \\
\text { Percentage of readings of: } \\
\text { Small opacities ( } 1 / 0 \text { or greater) } \\
\text { Rounded } \\
\text { Irregular } \\
\text { Large opacities (present) } \\
\text { Costophrenic angle obliteration } \\
\text { Pleural thickening (grade } 1 \text { or greater) } \\
\text { Irregular diaphragm (present) } \\
\text { Irregular cardiac border (present) } \\
\text { Pleural calcification } \\
\text { Additional symbols (at least one) } \\
\text { Less-than-normal }\end{array}$ & $\begin{array}{r}0.8 \\
1 \cdot 4 \\
1 \cdot 2 \\
4 \cdot 3 \\
2 \cdot 2 \\
1 \cdot 0 \\
0.3 \\
1 \cdot 6 \\
6 \cdot 1 \\
14 \cdot 5\end{array}$ & $\begin{array}{r}0.8 \\
5.1 \\
0.4 \\
2.6 \\
1.8 \\
1.4 \\
0.5 \\
1.5 \\
5.6 \\
18.6\end{array}$ & $\begin{array}{c}1702 \\
41 \cdot 2 \\
21 \cdot 3 \\
320 \\
15 \\
65 \cdot 1\end{array}$ & $\begin{array}{r}3.3 \\
15.9 \\
2.7 \\
11.8 \\
10.3 \\
7.3 \\
5.0 \\
6.6 \\
13.1 \\
47.6\end{array}$ & $\begin{array}{r}5 \cdot 0 \\
22 \cdot 4 \\
3 \cdot 2 \\
17 \cdot 9 \\
17 \cdot 9 \\
9 \cdot 4 \\
8 \cdot 5 \\
12 \cdot 4 \\
22 \cdot 6 \\
59 \cdot 1\end{array}$ \\
\hline
\end{tabular}

Table 3 Description of cohort 2 (988 men)

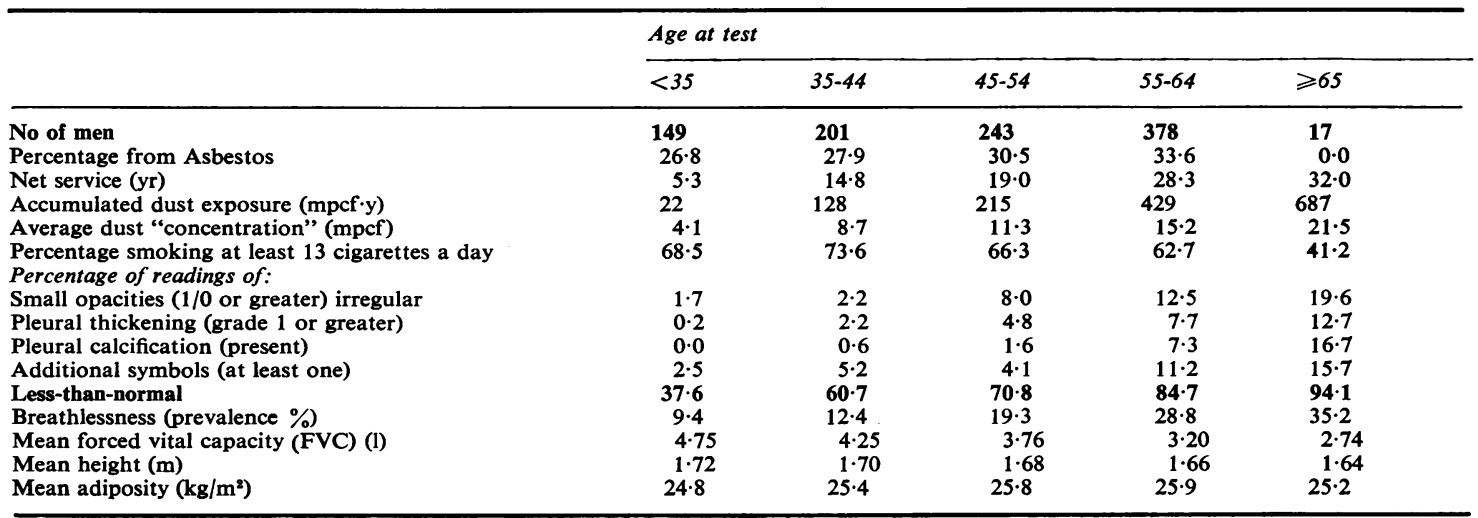


the foot of table 2 was reflected in each set, although its severity depended on the reader.

The first two lines of table 4 give the numbers of deaths (all causes) among the normals and less-thannormals in the two cohorts; the RRs were 1.74 and $1 \cdot 24$, with $\chi^{2}$ values (1 df) of 110.72 and 0.83 , respectively. When cohort 1 was split into three "eras" according to the years in which men left work, the RRs were consistent in each era. The distributions of man-years accumulated in the three eras of cohort 1 and in cohort 2 were all quite different, reflecting the principles of selection. The normals were, of course, considerably younger than the less-than-normals, but the RRs are based on ratios that take these differences into account. In cohort 1 the corresponding RR was assessed for each reader: they were $1.41,1.55,1.68,1.88,2.00$, and 2.01.

The remainder of table 4 concerns the five specific radiographic features, the RRs being in relation to the normals. For cohort 1 , values of $\chi^{2}(1 \mathrm{df})$ were huge (between 83.69 and 120.30 ) for all features except pleural calcification, but even here $\chi^{2}=$ 16.59. For cohort 2 , the RRs were reasonably similar for several features but because of the much smaller numbers the $\chi^{2}$ values were all quite small. The RRs (all causes of death) of cigarette smoking were $1.67\left(\chi^{2}=84.99\right)$ in cohort 1 and $1.88\left(\chi^{2}=10 \cdot 18\right)$ in cohort 2; those of accumulated dust exposure of at least $300 \mathrm{mpcf} \cdot \mathrm{y}$ were $1.59\left(\chi^{2}=75.37\right)$ and $1 \cdot 21\left(\chi^{2}=1 \cdot 10\right)$.

In the radiological classification used in 1967 the category 0/- of profusion of small opacities was introduced, using the phrase "barndoor" normal. ${ }^{16}$ This category was used very seldom, and mainly by one reader. In cohort 1 , however, it was possible to calculate SMRs for categories of combined profusion of small opacities as follows: 0/-: 0.87; $0 / 0$, without other changes: $1 \cdot 21 ; 0 / 0$, with other changes: $1.76 ; 0 / 1$ or more, with or without other changes: $2 \cdot 37$. The trend is clear, although not of high statistical significance.

Table 5 shows the distribution by cause of the 1427 deaths since 1951 in cohort 1 , together with the SMRs. The excesses of deaths were undoubted for most causes, as evidenced by large $\chi^{2}$ statistics (not shown); the exceptions were "other respiratory diseases" and "all other malignant diseases." Under the heading RR $¥$ is shown the risk for each group of causes in the less-than-normals relative to that in the normals. The risks were greatly enhanced for pneumoconiosis $(R R=11 \cdot 75)$, respiratory tuberculosis $(R R=6 \cdot 28)$, lung cancer $(R R=3 \cdot 24)$, and "other" respiratory conditions $(R R=2 \cdot 29)$; the associated values of $\chi^{2}$ lay between 44.63 and $12 \cdot 17$. Several other high $\chi^{2}$ statistics arose with RRs around 1.5 because of the large numbers of deaths.

Table 6 gives, for cohort 1, RRs of death from selected groups of causes associated with: (a) an assessment of less-than-normal; $(b)$ the presence of each radiographic feature; and (c) accumulated dust exposure at least $300 \mathrm{mpcf} \cdot \mathrm{y}$, and cigarette smoking (the last for men of known smoking habit only). For $(a)$ and $(c), \chi^{2}$ statistics (each with $1 \mathrm{df}$ ) were calculated in the usual way. For $(b)$, both RR and $\chi^{2}$ (again with $1 \mathrm{df}$ ) were found by comparing the mortality of those in whom the specific radiological feature was present against the normals, in an orthogonal partition of the three subcohorts: normals; less-than-normals involving the specific feature; and other less-than-normals.

For pneumoconiosis, each specific radiographic feature except pleural calcification led to RR more

Table 4 Radiographic changes and total mortality

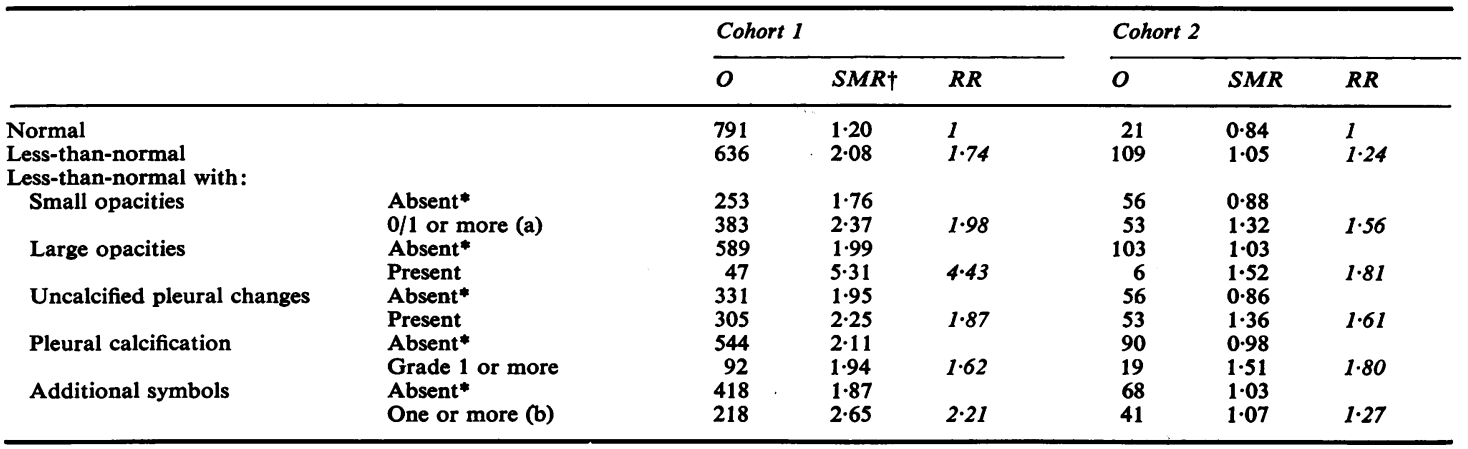

- From all six readings in cohort 2.

†Expectations were obtained by summation over three "eras," leaving a small gap in combined study intervals; thus SMRs in this column are all slightly overstated (by about $2 \frac{1}{2} \%$ ). RRs are virtually unaffected. Same comment applies to right hand part of table 5 .

(a) Either rounded or irregular.

(b) In $1967 \mathrm{U} / \mathrm{C}$ classification use of symbols was not obligatory. 
Table 5 Cause-specific mortality in cohort 1 in relation to radiological abnormality. (1427 deaths 1951-75, but excluding 11 of unknown causes)

\begin{tabular}{|c|c|c|c|c|c|c|c|c|}
\hline & \multicolumn{2}{|c|}{ Complete cohort } & & & \multirow[b]{2}{*}{$O$} & \multirow[b]{2}{*}{$S M R$} & \multirow[b]{2}{*}{$R R \ddagger$} & \multirow[b]{2}{*}{$x^{2}$} \\
\hline & $O$ & $S M R$ & & & & & & \\
\hline Pneumoconiosis $(523-524)^{*}$ & 31 & $34 \cdot 07$ & $\begin{array}{l}\text { Normals } \\
\text { Less-than-normals }\end{array}$ & & $\begin{array}{r}5 \\
26\end{array}$ & $\begin{array}{r}8 \cdot 20 \\
96 \cdot 30\end{array}$ & $11 \cdot 75$ & $41 \cdot 24$ \\
\hline Lung cancer (162-164) & 119 & $1 \cdot 77$ & $\begin{array}{l}\text { Normals } \\
\text { Less-than-normals }\end{array}$ & & $\begin{array}{l}49 \\
70\end{array}$ & $\begin{array}{l}1 \cdot 08 \\
3 \cdot 50\end{array}$ & $3 \cdot 24$ & $44 \cdot 63$ \\
\hline Respiratory tuberculosis $(002-008) \dagger$ & 40 & $3 \cdot 38$ & $\begin{array}{l}\text { Normals } \\
\text { Less-than-normals }\end{array}$ & & $\begin{array}{l}12 \\
28\end{array}$ & $\begin{array}{l}1 \cdot 42 \\
8 \cdot 92\end{array}$ & $6 \cdot 28$ & $37 \cdot 28$ \\
\hline $\begin{array}{l}\text { Other respiratory diseases } \\
(470-552 ; 525-527)\end{array}$ & 67 & $1 \cdot 27$ & $\begin{array}{l}\text { Normals } \\
\text { Less-than-normals }\end{array}$ & & $\begin{array}{l}31 \\
36\end{array}$ & $\begin{array}{l}0.90 \\
2 \cdot 07\end{array}$ & $2 \cdot 29$ & $12 \cdot 17$ \\
\hline Diseases of the heart $(400-443)$ & 566 & $1 \cdot 36$ & $\begin{array}{l}\text { Normals } \\
\text { Less-than-normals }\end{array}$ & & $\begin{array}{l}331 \\
235\end{array}$ & $\begin{array}{l}1 \cdot 20 \\
1 \cdot 83\end{array}$ & $1 \cdot 53$ & $25 \cdot 25$ \\
\hline $\begin{array}{l}\text { Cancer of oesophagus or stomach } \\
(150-151)\end{array}$ & 53 & $1 \cdot 70$ & $\begin{array}{l}\text { Normals } \\
\text { Less-than-normals }\end{array}$ & & $\begin{array}{l}30 \\
23\end{array}$ & $\begin{array}{l}1 \cdot 47 \\
2 \cdot 32\end{array}$ & $1 \cdot 58$ & $2 \cdot 79$ \\
\hline $\begin{array}{l}\text { All other malignant diseases } \\
(140-148 ; 152-161 ; 165-205)\end{array}$ & 146 & $1 \cdot 10$ & $\begin{array}{l}\text { Normals } \\
\text { Less-than-normals }\end{array}$ & & $\begin{array}{l}83 \\
63\end{array}$ & $\begin{array}{l}0.95 \\
1 \cdot 51\end{array}$ & $1 \cdot 59$ & $7 \cdot 78$ \\
\hline Cerebrovascular diseases $(330-334)$ & 101 & $1 \cdot 44$ & $\begin{array}{l}\text { Normals } \\
\text { Less-than-normals }\end{array}$ & $r^{\prime}$ & $\begin{array}{l}62 \\
39\end{array}$ & $\begin{array}{l}1.39 \\
1.62\end{array}$ & $1 \cdot 17$ & $0 \cdot 59$ \\
\hline Accidents (800-999) & 110 & 1.79 & $\begin{array}{l}\text { Normals } \\
\text { Less-than-normals }\end{array}$ & & $\begin{array}{l}72 \\
38\end{array}$ & $\begin{array}{l}1 \cdot 62 \\
2 \cdot 56\end{array}$ & $1 \cdot 58$ & $5 \cdot 24$ \\
\hline Other known causes (Remainder) & 183 & $1 \cdot 25$ & $\begin{array}{l}\text { Normals } \\
\text { Less-thàn-normals }\end{array}$ & & $\begin{array}{r}107 \\
76\end{array}$ & $\begin{array}{l}1.09 \\
1.67\end{array}$ & $1 \cdot 53$ & $8 \cdot 12$ \\
\hline
\end{tabular}

* Codes in 7 th revision of the International Classification of Diseases.

+ No death was coded 001 .

$\$ R R$ is cause-specific $S M R$ in less-than-normals divided by SMR in normals.

Table 6 Deaths from specific causes related to radiographic changes, dust exposure, and smoking. (Risks relative to normals, or to unexposed, and $\chi^{2}$ statistics)

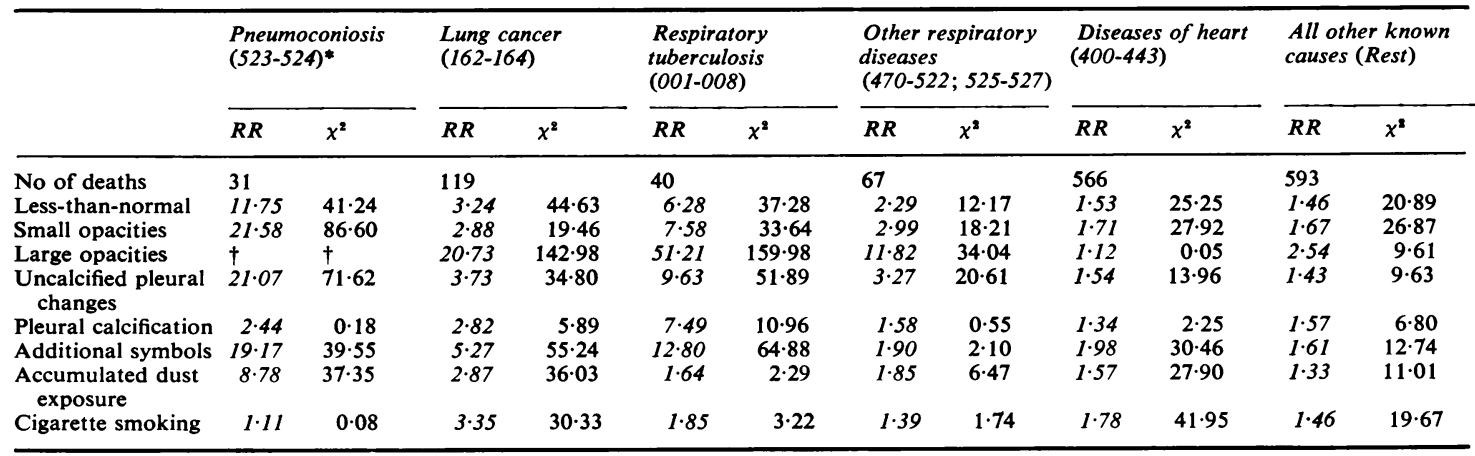

* Codes in 7 th revision of the International Classification of Diseases.

+Only four of the 31 deaths were in men in whose films large opacities had been recorded; the expectation was too small to be computed to two decimal places, leading to unmeasurably large $\mathbf{R R}$ and $x^{2}$.

than twice as great as that associated with higher dust exposure; the smoking effect was small. There were only three pneumoconiosis deaths in cohort 2 , all in less-than-normals. The presence of each radiographic feature was associated with enhanced risk of lung cancer in cohort 1, the strongest association being with large opacities. RRs were in most cases lower than for pneumoconiosis, although $\chi^{2}$ values were fairly high because of many more deaths. The RR of those more heavily exposed to dust was considerably lower for lung cancer $(2 \cdot 87)$ than for pneumoconiosis $(8 \cdot 78)$, although $\chi^{2}$ values were similar, but smoking had by no means a negligible effect in cohort $1\left(\mathrm{RR}=3 \cdot 35, \chi^{2}=30 \cdot 33\right)$ and was the only factor to provide a conventionally "significant" effect in cohort $2\left(\mathrm{RR}=4 \cdot 11, \chi^{2}=\right.$ 6.10).

Although respiratory tuberculosis was once common in Quebec, there were no deaths from this cause in either cohort after 1966. Not surprisingly, the risks of the less-than-normals were much higher than those of the normals. It is well-known that the radiological appearances of tuberculosis can be confused with pneumoconiotic large opacities $(\mathrm{RR}=51 \cdot 21)$, while the "additional symbols" $(R R=12 \cdot 80)$ include means of recording diagnoses 
of tuberculosis. It may be noted that the dust effect $(R R=1.64)$ was not nearly so large as that associated with abnormality of radiograph (RR at least 6.28). In cohort 1 deaths from other respiratory diseases were also predictable from large radiographic opacities (but not in cohort 2, where depressed lung function was a better predictor). In cohort 1 the dust effect was considerable, so that high RRs for the men with other pneumoconiotic changes may well have reflected heavier exposure.

Although RRs for diseases of the heart were generally lower (between 1.12 and 1.98), some values of $\chi^{2}$ were large because they were based on many deaths. The dust and pneumoconiotic effects may reflect deaths from heart disease secondary to fibrosis. The "additional symbols" associated with high risk may have included those relating to heart conditions-for instance, cor pulmonale or enlarged heart. The smoking effect was to have been expected from other studies in asbestos workers ${ }^{5}$ and in other populations (see several reports summarised by Holman ${ }^{17}$ ). The RRs of all other known causes of death were, in most cases, among the lowest for each factor examined, but, as before, large numbers of deaths led to high values of $\chi^{2}$ in several cases. Asbestos-related disease and smoking may contribute to death in any life-threatening condition.

\section{A POSTERIORI REASONING}

Parenchymal change was recorded in $23(74.2 \%)$ of the 31 deaths certified as pneumoconiosis, but five were normal. The other three were: pleural thickening (1); left costophrenic angle obliteration and an "additional symbol" (1); and a single additional symbol (1). (Unfortunately, it has not yet been feasible to discover which particular additional symbol had been recorded in these two cases.) The distributions of parenchymal changes are given in table 7(a). Among the 23 readings of small opacities, there were three where the rounded shape predominated (one case each of p, q, and r) and 20 with irregular opacities, 12 of size u. In four films large opacities had been seen, each in association with small opacities of profusion at least $2 / 2$. The median profusion of small opacities in the 23 films was $2 / 2$.

Each of the 31 case-control pairs was classified according to whether "pneumoconiotic change" (that is, small or large opacities, pleural thickening or calcification) was: (a) present in both members of the pair (seven pairs); (b) present only in the case (17 pairs); (c) present only in the control (two pairs); and $(d)$ absent in both (five pairs). The appropriate test ${ }^{18}$ is based on the numbers in $(b)$ and $(c)$ only. The modifications proposed by Pirie and Hamdan ${ }^{19}$ have been incorporated. Such numbers were too small for a test for each reader separately, but $(b)$ was larger than $(c)$ for five readers and equal for the sixth. Pooling yielded $\chi^{2}=11.07$, which provides some confidence that the excess of pairs in $(b)$ over those in $(c)$ was not due purely to chance.

One death from pneumoconiosis was found to have occurred in a man with recorded accumulated dust exposure less than $30 \mathrm{mpcf} \cdot \mathrm{y}$; his last job had apparently been at Thetford Mines in 1930, at least 15 years before radiology was started there, and a substantial further history of exposure was subsequently traced. Even including this man in the analysis, however, there was a clear relation of risk to dust exposure; there was no corresponding relation with smoking. Finally, we wished to discriminate between those 23 pneumoconiosis deaths in which the radiograph had shown pneumoconiotic

Table 7 Parenchymal changes in deaths from pneumoconiosis and lung cancer

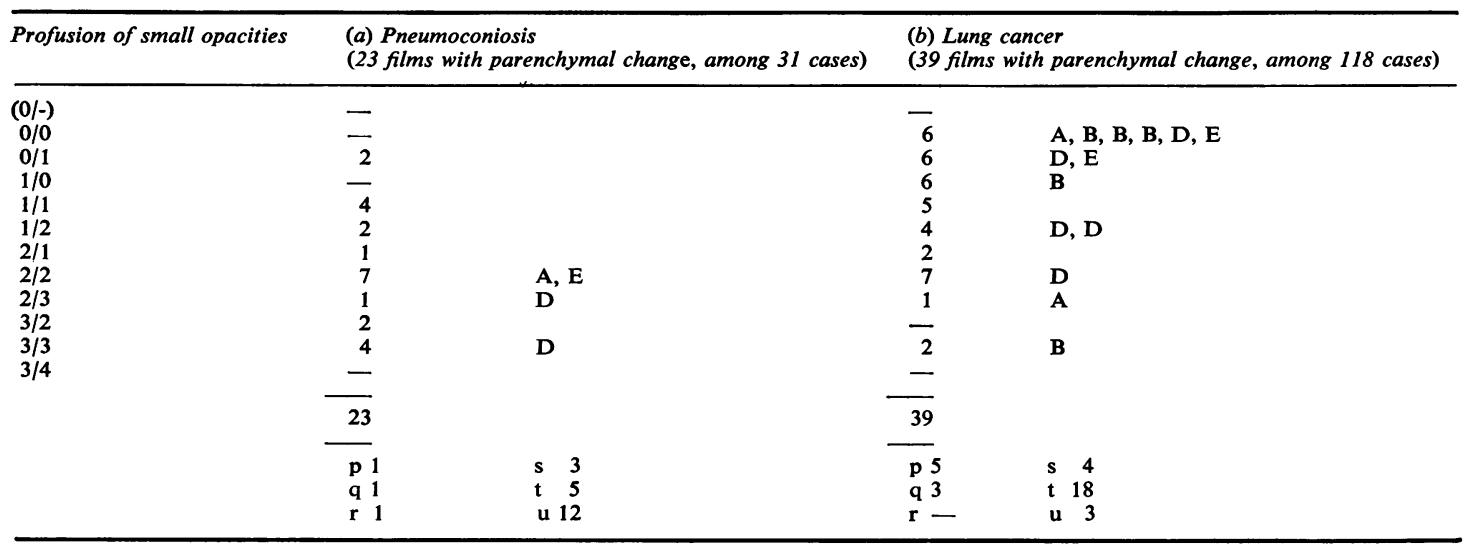

Capital letters refer to large opacities: $A, B$, and $C$ well defined; D, E, and $F$ poorly defined. 
change and the other seven (excluding the man with incomplete history). All 30 had accumulated dust exposure of at least $100 \mathrm{mpcf} \cdot \mathrm{y}, 20$ of those with change $(87 \%)$ and four of those without change $(57 \%)$ having been exposed to $300 \mathrm{mpcf} \cdot \mathrm{y}$ or more. The interval between last recorded job and death was less than five years in 13 of those with change and in four of those without change $(57 \%$ in both cases). The difference between those with and without change is small for dust exposure, and trivial for the other factor.

The investigation of deaths from lung cancer followed similar lines. The number of deaths was increased from the 119 shown in tables 5 and 6 by two that occurred before 1951, but reduced by three which, although coded 162 or 163 , were in fact found to be from mesothelioma-see below. The pattern of radiographic change in these 118 cases was quite different from that in the deaths from pneumoconiosis: firstly, there was a much higher proportion of normals $(48$, or $40.7 \%)$ compared with $16.1 \%$ in pneumoconiosis; secondly, not only was the proportion of the less-than-normals showing parenchymal change rather lower than in pneumoconiosis cases $(55.7 \%$ compared to $88.5 \%)$, but such parenchymal changes as were recorded were also rather different in character (table 7(b)). In lung cancer, compared with pneumoconiosis, the profusion of small opacities was substantially lower (median 1/1), they were more often rounded, and of 25 with irregular small opacities 18 were of size $t$; finally, in 14 cases in which large opacities had been recorded, only three were associated with small opacities of profusion $2 / 2$ or greater, and six had no background of small opacities.

The 118 case-control pairs were classified as: (a) both members less-than-normal ( 24 pairs); $(b)$ case less-than-normal but control normal (46 pairs); (c) case normal but control less-than-normal (14 pairs); and $(d)$ both normal (34 pairs). For all readers, the number of pairs in $(b)$ was greater than that in $(c)$, and for two readers the $\chi^{2}$ statistic was substantial (7.52 and 5.56). Pooling over readers produced $\chi^{2}=16 \cdot 54$, a little higher than for pneumoconiosis, but arising more on account of the larger numbers than because of better discrimination.

The expected dose-response relations were found both for dust exposure (the RR for those who had accumulated at least $300 \mathrm{mpcf} \cdot \mathrm{y}$ relative to the less heavily exposed being 1.67) and for cigarette smoking (RR for current smokers, compared with others, being $3 \cdot 44)$, but neither factor discriminated well between normals and less-than-normals. The longer the interval, however, between last recorded job (usually less than a year after the radiograph had been taken) and death, the higher the probability of the film being normal: where the interval was less than five years, there were nine normals among 48 cases $(18.8 \%)$; for interval five but less than 10 years, there were 16 normals in 36 cases $(44.4 \%)$; interval 10 but less than 20 years, yielded nine normals in 14 cases $(64.3 \%)$; and interval at least 20 years provided 14 normals in 20 cases $(70.0 \%)$. In 11 of the 14 cases of lung cancer in whose films "large opacities" had been assessed, the interval was less than five years; in the six cases with "large opacities" but no small opacities, the intervals were all short, three of the men dying in the same year as that of his last job, two in the following year, and one in the year after that.

A total of six deaths within the two cohorts had been recognised during the main mortality study as due to malignant mesothelial tumour, all of the pleura. The films of those who died from within about a year of the radiograph being taken had been read as follows: (1) t, $0 / 1$; (2) right diaphragm irregular and pleural calcification of grade 3 ; and (3) one additional symbol. The other three films had been taken five to nine years before death, and the readings were: (4) p, 1/0; and (5) normal; the sixth case (in cohort 2) had been assessed as showing pleural calcification by all six readers; three readers had recorded minor parenchymal change $(\mathrm{p}, 0 / 1$; $t, 0 / 1 ; u, 1 / 0)$ and a fourth that both diaphragms were irregular.

\section{Discussion}

Asbestos workers and others exposed to dusts are $x$-rayed periodically for two main reasons. Firstly, it is hoped that minimal signs of pathological effects will be discovered sufficiently early to enable workers to be removed from exposure before they suffer further. Secondly, the radiographic findings, taken collectively, can be used to monitor the working environment as a guide to whether and where more stringent dust control is required. Both these objectives are dependent on how well chest radiographs, and those who read them, can record the early signs of important disease. Even so, there remains the question of whether removal from exposure is an effective measure of protection for those showing radiographic changes. In fact, we already have direct and indirect evidence for believing that the value of removal is bound to be limited. In a follow-up study of 86 men who had left the chrysotile industry between 1950 and 1961 a sizeable proportion showed increased parenchymal change when re-examined in $1972 .{ }^{20}$ The indirect evidence is also strong: our cohort mortality studies showed no sign of a threshold in the exposure-response relations for either lung cancer or pneumoconiosis. Thus any 
employees exposed long enough to manifest dustrelated changes on radiographs must inevitably and already be at increased risk of death from these diseases. Even though the protection afforded by periodic examination is not complete, however, it may still be useful, provided that the changes read are valid and have prognostic significance.

The effects of asbestos are fibrogenic and carcinogenic. In pathological terms these responses are distinct, and, while both appear to be directly related to exposure, they may or may not occur independently. The histological and morbid anatomical changes characteristic of asbestosis are reflected in the development of the UICC/Cincinnati and ILO U/C classifications that were created to allow recording of irregular parenchymal opacities and pleural thickening. It would thus be of serious concern if the occurrence of these radiographic changes did not forecast mortality from pneumoconiosis and its complications to a useful degree. Our findings show that this aim was achieved reasonably well and that some of the failures could be explained. Nevertheless, in cohort 1 (and based on study intervals without gap; see footnote $\dagger$ to table 4) the SMR (all causes) for men whose radiograph was read as completely normal was 1.17 (an excess of 116 over expectation of 675), compared with 1.44 for the total cohort (overall excess of 437 against expectation 990). Thus these routine radiographs failed to detect $27 \%$ of the excess mortality, presumably attributable to exposure to asbestos. This interpretation is somewhat optimistic in that a high proportion of deaths took place within a year or two of the radiograph when, even had abnormalities been detected, no improvement in outcome could have been expected. Clues to the cause of this failure, but no certain explanation, can be inferred from table 5 . Of about 437 excess deaths in cohort 1 , only $124(28 \%)$ were caused by respiratory diseases, and in these the ratio of the SMRs was considerably higher than the average for all causes. This suggests that the main failure of the radiograph to predict mortality was in deaths where asbestosis was a contributory rather than the primary cause. This does not mean that the readers were unable to detect changes in these cases; their success with the respiratory deaths suggests that they could. It implies, rather, that they could not discriminate well between those who were or were not affected by some other life-threatening.disease-which is hardly surprising. It would also be unreasonable to expect the readers to distinguish smokers from nonsmokers. Because tobacco is at least as important as asbestos in causing cardiorespiratory disease and lung cancer, discrimination by radiograph alone is bound to be limited.
The nature of the association between pulmonary fibrosis and lung cancer in asbestos workers is a matter of theoretical interest and medicolegal importance, which our findings do not wholly clarify. In cohort 1 the SMR of 1.77 for lung cancer implies an occupational excess of perhaps 52 deaths, many by virtue of the interaction between asbestos and smoking. The analysis of parenchymal changes among 118 of these cases shows that in only 33 were small opacities read. If we could assume that all 33 were part of the 52 excess cases this proportion $(63 \%)$ would be little lower than the 23 out of $31(74 \%)$ for pneumoconiosis deaths. Although there is no way of specifically identifying the excess cases, the assumption is supported by the relatively high level of discrimination ( $R R=2.88)$ on the basis of small opacities alone. Indeed, from the material on which table 5 is based, we found that 49 of the 52 excess deaths from lung cancer were among men whose radiographs were less than normal, 33 showing small opacities. This suggests that most, but not necessarily all, cases of lung cancer attributable to chrysotile exposure in mining and milling probably have small parenchymal opacities before death. Presumably, histological evidence would be more sensitive.

These conclusions may not apply to other types of asbestos fibre or industrial exposure where the risks of cancer, relative to fibrosis, differ; they are not generalisable to other readers and less wellcontrolled circumstances. The opportunities for subjective bias in $x$-ray reading are notorious. Without meticulous observation of well-tried rules, developed to ensure objectivity, ${ }^{21}$ the levels of validity, sensitivity, and specificity shown in this study might well be reduced. On the other hand, better film quality, more highly standardised technique, and perhaps some improvement in the classification could produce even better results.

We thank our many colleagues, including film readers, hygienists, field workers, epidemiologists, and programmers, and also employees and management, who provided and processed the data for this study. The project was carried out while one of us (FDKL) was on sabbatical leave from McGill University; it was supported by a grant from the Institute of Occupational and Environmental Health of the Quebec Asbestos Mining Association.

\section{References}

${ }^{1}$ McDonald JC, McDonald AD, Gibbs GW, Siemiatycki J, Rossiter CE. Mortality in the chrysotile asbestos mines and mills of Quebec. Arch Environ Health 1971;22:67786.

${ }^{2}$ McDonald JC, Becklake MR, Gibbs GW, McDonald 
AD, Rossiter CE. The health of chrysotile asbestos mine and mill workers of Quebec. Arch Environ Health 1974;28:61-8.

${ }^{3}$ Liddell FDK, McDonald JC, Thomas DC. Methods of cohort analysis: appraisal by application to asbestos mining. $J$ R Stat Soc A 1977;140:469-91.

${ }^{4}$ McDonald JC, Liddell FDK. Mortality in Canadian miners and millers exposed to chrysotile. Ann NY Acad Sci 1979;330:1-10.

${ }^{5}$ McDonald JC, Liddell FDK, Gibbs GW, Eyssen GE, McDonald AD. Dust exposure and mortality in chrysotile mining, 1910-75. Br J Ind Med 1980;37:11-24.

${ }^{6}$ Gibbs GW, Lachance M. Dust exposure in the chrysotile asbestos mines and mills of Quebec. Arch Environ Health 1972;24:189-97.

${ }^{7}$ McDonald JC, Becklake MR, Fournier-Massey G, Rossiter CE. Respiratory symptoms in chrysotile asbestos mine and mill workers of Quebec. Arch Environ Health 1972;24:358-63.

${ }^{8}$ Yule GU. On some points relating to vital statistics, more especially statistics of occupational mortality. Section 1 : Standardization. J R Stat Soc 1934;97:1-26.

${ }^{9}$ Becklake MR, Fournier-Massey G, Rossiter CE, McDonald JC. Lung function in chrysotile asbestos mine and mill workers in Quebec. Arch Environ Health 1972;24:401-9.

${ }^{10}$ Bohlig H, Bristol LJ, Cartier PH, et al. UICC/Cincinnati classification of the radiographic appearances of pneumoconioses. Chest 1970;58:57-67.

$"$ Becklake MR, Fournier-Massey G, McDonald JC,
Siemiatycki J, Rossiter CE. Lung function in relation to chest radiographic changes in Quebec asbestos workers. Bulletin de Physio-pathologie Respiratoire 1970;6:637-59.

12 Rossiter CE, Bristol LJ, Cartier PH, et al. Radiographic changes in chrysotile asbestos mine and mill workers of Quebec. Arch Environ Health 1972;24:388-400.

${ }^{13}$ Liddell FDK. Mortality of Quebec chrysotile workers in relation to radiological findings while still employed. London University, 1978. (PhD thesis.)

${ }^{14}$ ILO. ILO U/C international classification of radiographs of the pneumoconioses, 1971. Geneva: ILO, 1972. (Occupational Safety and Health Series No 22 (revised).)

15 Armitage P. Statistical methods in medical research. Oxford: Blackwell, $1971: 362-7$.

${ }^{16}$ Liddell FDK. An experiment in film reading. $\mathrm{Br} \mathrm{J}$ Ind $\mathrm{Med}$ 1963;20:300-12.

17 Holman PB (ed). The health consequences of smoking. Atlanta: Centre for Disease Control, US Department of Health, Education and Welfare, 1976.

${ }^{18}$ McNemar Q. Note on the sampling error of the differences between correlated proportions or percentages. Psychometrika 1947;12:153-7.

19 Pirie WR, Hamdan MA. Some revised continuity corrections for discrete distributions. Biometrics 1972;28: 693-701.

${ }^{20}$ Becklake MR, Liddell FDK, Manfreda J, McDonald JC. Radiological changes after withdrawal from asbestos exposure. Br J Ind Med 1979;36:23-8.

${ }^{21}$ Weill $H$, Jones $R$. The chest roentgenogram as an epidemiologic tool. Arch Environ Health 1975;30:435-9. 